\title{
BREVES INCENDIOS
}

Gema Santamaría

\section{1. \\ EL ATARDECER ENROJECE FRENTE A NOSOTROS}

El cielo se marca todo como una furia

y el mar hace lo propio a nuestros pies:

olas montándose unas a otras

como crestas rompiendo

violentamente los celestes del agua.

Sobre una piedra, un grupo de personas se empina a observar la marea y su malestar.

Sus cuerpos tan unidos simulan un coral suavizado por el menear de sus cabezas.

Vemos cómo el agua los devora a lengüeteadas en un instante.

Nos reímos porque sí, porque tanta belleza suscita en nosotros siempre un poco de crueldad.

Me cuesta entender estos atardeceres enrojecidos, entender si su furia es una furia enamorada o enloquecida. Frente a ellos siento un golpeteo apacible en el pecho y una dosis de terror mordisqueándome las piernas.

Dicen que admiramos los atardeceres en demasía. Pero yo observo su doliente resplandor y sospecho que aún hoy, después de tanto tiempo, nos estremecemos ante su rabia. 


\title{
2. \\ ÍNDIGO
}

\author{
A María Antonia
}

Hemos de ver la puesta del sol, la roja mirada,

el candor y la furia.

Sobre las piedras

arden las últimas horas.

En un arrebato

la luz se modifica.

Intuimos la trayectoria de las sombras.

Somos solitaria presencia,

testigos únicos del cauce

cerrándose frente a nosotros.

Los pájaros guardan silencio a estas horas,

las piedras se retraen sobre sí mismas

hurgando su musgo más íntimo.

Una grieta nace entre las montañas.

Las aguas de la noche se desperezan:

de ellas emerge un torrente de peces húmedos.

El rojo se convierte en un índigo intenso, el cuerpo fiero de la noche se avecina.

Partimos en el momento justo, la mejilla del mar asciende suave y toca los riscos obscurecidos.

Satisfechas, caminamos cuesta abajo, hacia la boca abierta de la luna. 


\section{3.}

\section{QUIZÁS LA MEDIANOCHE}

Despertamos en la orilla de otro sueño.

Desde aquí, observamos el vaivén de la historia, la pequeña historia, la gran historia, la que imaginábamos en péndulo, la que hoy sabemos espiral.

A tientas reconocemos los espejos.

Hemos llegado a un abismo conocido e íntimo, ¿cuántas vueltas más antes de despertar?

Crecen los verdes a pesar del tiempo gris y las revueltas, crecen flores, crecen manos, crecen los bordes de la cotidianidad.

La memoria se dobla sobre sí misma. Nos reconocemos en los cuerpos olvidados, en las tumbas hacedoras de milagros, en el atardecer siempre enrojecido de la ciudad.

Somos viajeros en mitad de la espesura $\mathrm{y}$, sin embargo, crecen verdes en las piedras, crecen flores, crecen manos, y en el borde de lo insólito la cotidianidad.

Quizá la medianoche es más luz de lo que creemos, $y$ en el delirio de sus horas se gesta el sueño de lo que siempre, sin intuirlo, pudimos ser. 


\section{4. \\ NAUfRAGios}

Al Padre Flor María Rigoni

En este viaje, Padre, ¿en cuántos exilios pensaste?

¿En qué tierra abandonaste los ojos,

por no hablar del corazón,

el estómago y las manos?

Pienso en ti y en la estéril espuma de los aeropuertos.

Pienso en ti, con tu sotana hecha de plumas, dejando poemas

arqueados en mitad de la penumbra.

¿Qué escribes cuando ves el duty free?

¿Qué verso te provoca el paso descalzo por el checkpoint migratorio?

Pensarás en los ojos heridos de aquellos que han llorado frente a ti, en este mundo hecho de hierro y de papel

y de criaturas apiladas como balas sobre los carruajes de la desesperanza.

No conozco más que la fiebre de tu risa

y tu bendición que es como una espina suavizada por la lluvia.

No conozco de tus extrañezas ni de tus soledades,

pero intuyo tus rezos en la humedad de las ventanas matutinas

y tus enojos

como un estruendo de gigantes al pie de las acacias. 
En este viaje, Padre, pienso en ti.

En tu encuentro a diario con lo profano,

en tu cama como una balsa navegando sobre las flores del mal.

Padre, cuando sueñas,

¿de qué color son las frentes de los refugiados?,

¿qué ropas llevan los ahogados en tu barco?,

¿cuál la corona de flores que llevan al resucitar?

En el río de tu frontera, ¿cuántos muertos?

En el río de tu frontera, ¿cuántos rezos?

En el río de tu frontera, ¿dónde nace la luz?

En este viaje, Padre, solo la poesía.

En este viaje,

solo tu presencia forma hojarascas apacibles

sobre las cuales andar. 


\section{5. \\ Noche EN MANAGUa, \\ TRAS LA MUERTE DE LOS GALLOS}

Esta noche tiene la garganta enrojecida.

Ha gritado y está enferma.

Duerme al fondo de un cuarto blanco e iluminado sobre el piso.

Es un gran cerdo rosado.

Contra la esquina, se lamenta.

Perdió la lucidez y tiene todas las uñas rotas.

Está mareada

está borracha.

Esta noche no tiene una cama donde orinar sus miedos.

Por eso se arrastra sobre los techos enmohecidos.

Se alimenta del musgo y del vapor que dejan los niños, al dormir, en las ventanas.

Se han muerto los gallos que ponen fin a su delirio.

Solo los grillos crepitan en el jardín eterno de las horas.

Está sola con su boca ratonera

está tensa

está brava y es caliente.

Nosotros dormimos en la mancha gris

que es su garganta.

Nos creemos soñadores.

Aún no hemos probado el filo.

Ni siquiera intuimos sus navajas. 
6.

\section{EL LUGAR MÁS ÍNTIMO \\ PARA PROVOCAR INCENDIOS}

La cocina. El infierno.

Un lugar de cuchillos y de sangre.

Es ahí donde arde el aceite

donde mi madre heredó su cicatriz más profunda.

Dicen que es el lugar de la abundancia

del dulce y tibio olor a leche

del tomate fresco,

luciendo su más firme color rojo.

Recuerdo las cebollas

crispándose en la cuna,

ajos como pequeñas larvas

agitándose en el fuego.

Mamá con un delantal que le cubría el pecho, la sangre de la carne cruda, las verduras y los trastos bajo la misma regadera, las especias calentándose en el mismo olor a grasa. 
El lugar más íntimo para provocar incendios.

Mamá huele a aceite, tiene quemaduras en los ojos, sus pequeñas manos son muy torpes.

El agua hierve, la carne se ablanda, cáscaras y huesos en una bolsa plástica.

En la cocina, restos y paredes salpicadas; en la mesa, manteles y cucharas limpias.

Una abeja arde en la cocina. Atrapada en un vaso boca abajo, se va poniendo sucia. 


\section{7.}

\section{ENTREVISTA A UNA EXPERTA \\ EN VIOLENCIA}

Así es que díganos,

¿de qué color es la herida que resulta de un golpe a puño cerrado

precedido por el enojo (también cerrado)

del otro que se avecina y se lanza contra el cuerpo de aquel que de ahora en adelante ocupa la categoría científica de "víctima"?

¿Cuál es el ritmo de la respiración?

¿A qué sabe la saliva cuando el cuerpo siente el miedo subírsele a la garganta como una fiera adolorida?

¿Será cierto que la boca se pone agria y un tanto seca y un poco tensa al punto de volverse un temblor involuntario?

\section{¿Y los ojos?}

¿Qué hacen los ojos ante el golpe?

Se cierran o más bien se dilatan, queriendo quedarse quietos y abiertos como para escapar de la pesadilla que no puede ser abandonada puesto que no hubo ni habrá sueño.

Todo es un día que da vueltas

y aquello en el centro más duro de esas volteretas

es la persona misma diciendo para sí: abre los ojos. 
¿Y las rodillas?

$¿$ Cierto que pierden su firmeza, que el hueso deja de ser una piedra del complejo mecanismo para volverse suave, torpe y llenarse toda de agua, que las piernas se convierten en cuatro músculos desesperados, extraviados: el sostén del cuerpo vuelto una suave y líquida cobardía?

¿Y el estómago?

Cuánto tarda en revolverse, en convertirse en un espasmo, en una sola náusea.

¿Y cuál es el sonido que nace del dolor, físico e inescapable, de aquel que ha sentido el calor de una herida en la cara, en las mejillas, cuál, la urgencia que transmite?

Así es que díganos:

a qué huele la muerte

cuánto pesa la muerte

dónde se escribe muerte

dónde se entiende muerte

¿Cómo es que se llamará su próximo artículo? 


\section{8. \\ BLACK FRIDAY}

A Jdimytai Damour

q.e.p.d.

Viernes negro. Un hombre murió aplastado.

Una estampida de compradores furiosos le pasó encima.

El suyo era un trabajo temporal, pasajero.

Era un empleado informal, un uniforme más en la cadena de supermercados Walmart.

Imagino cómo habrán crujido sus huesos,

si su boca se habrá abierto, si habrá escupido sangre

en el último minuto, si dijo algo, si tosió algo,

si la lengua se le enredó

en mitad de la asfixia.

Imagino si anunciaban las últimas ofertas,

el pasillo en el que se encontraban las rebajas.

Si como soundtrack sonaba una canción navideña

Oh, what fun it is to ride

in a one horse open sleigh

Imagino si ese ejército atolondrado sintió su cuerpo,

el blando estallido de su estómago,

el reacomodo de la carne,

las costillas desmenuzándose en el piso.

Dicen que la venta continuó toda la noche

que la mayoría de los clientes así lo quiso

Navidad en Nueva York

Oh, jingle bells, jingle bells,

jingle all the way... 
9.

\section{0:30 DE LA MAÑANA Y AÚN NO ESTAMOS LISTOS}

Murió un pájaro

en la entrada de tu casa.

Una criatura apenas

un cuerpo apenas

sin sangre.

Alas negras entre las hojas

simulando el gesto revuelto,

la tensa agonía por la supervivencia.

Estaba tan molesta

la señora vecina,

como si algo se le hubiese ido

en esa muerte.

Y nosotros,

tan en el café de la mañana,

en la discusión somnolienta de cada día.

Apenas atinamos a salir al patio, ensayar un rostro cabizbajo

y mirar no con poca repugnancia

el trozo de carne muerta.

Esa señora tiene unos setenta años,

tendrá la misma edad a la que murió mi abuela.

¿Será que lo que perdió ella en ese pájaro

lo perdimos nosotros hace tiempo?

Indiferentes, cerramos la puerta

y bebemos el resto de nuestro

café ya tibio. 
10.

\section{LA MADRE ERA LA CASA}

Nada se gesta fuera de la casa.

Fuera de la casa, mueren las flores y los pinos.

El frío con su boca tiesa, con su cuchilla, aguarda.

Las manos de los niños van perdiendo su destreza.

Una extraña nostalgia reblandece sus cuerpos retraídos.

Nada se gesta fuera de la casa.

Las crías hurgan el pasto

con sus rodillas aún limpias.

Prueban la tierra, el agua que se abre debajo de las piedras.

La niña dibuja un sol y, bajo el sol, una pradera donde su pelo aprenda a crecer en orfandad. 